\title{
Mycobacterium gastri
}

National Cancer Institute

\section{Source}

National Cancer Institute. Mycobacterium gastri. NCI Thesaurus. Code C86540.

A species of aerobic, Gram positive, rod shaped bacterium assigned to the phylum

Actinobacteria. This species is acid fast, nonmotile, grows on Lowenstein-Jensen medium, and does not grow in the presence of ethambutol or isoniazid. M. gastri is found in soil and water, occasionally in human stomach contents, is rarely associated with human disease and may be considered nonpathogenic. 